\title{
Problemen omtrent partus en neonatale sterfte bij raskatten: een studie bij Vlaamse fokkers
}

\section{Problems on parturition and neonatal mortality in Flemish pedigree cats: a questionnaire-based study}

\author{
J. De Moor, A. Van Soom, E. Wydooghe \\ Vakgroep Verloskunde, Voortplanting en Bedrijfsdiergeneeskunde, \\ Faculteit Diergeneeskunde, Universiteit Gent, \\ Salisburylaan 133, B-9820 Merelbeke, België
}

Jana.Demoor@Ugent.be

\section{AMENVATTING}

Hoewel het fokken met raskatten aan populariteit wint, zijn weinig wetenschappelijke gegevens beschikbaar omtrent de partus en de problemen die hierbij kunnen optreden. In verschillende studies werd aangetoond dat kittensterfte bij fokkers varieert van 15 tot $40 \%$. Aan de hand van een enquête bij fokkers werden in deze studie gegevens over 151 nesten verzameld van zes populaire rassen in Vlaanderen. De gemiddelde drachtduur bedroeg $65,1 \pm 2,64$ dagen. De gemiddelde nestgrootte bedroeg $4,5 \pm 1,73$ kittens. Kattinnen ouder dan vier jaar hadden een significant kleinere nestgrootte $(3,6 \pm 1,48$ kittens) dan katten jonger dan vier jaar $(4,8 \pm 1,71$ kittens) $(P=0,001)$. Bij $8,5 \%$ van de nesten werd bij de kattin een keizersnede uitgevoerd. Congenitale afwijkingen werden gerapporteerd bij $\mathbf{6 , 8 \%}$ van de nesten. Het totale sterftepercentage tot de speenleeftijd bedroeg in de voorliggende studie $21,4 \%$. Bij een kleinere nestgrootte (1-3 kittens: $12,2 \%)$, evenals bij grotere nesten (6-9 kittens: $7,3 \%)$ werd een significant hoger aantal doodgeboorten vastgesteld dan bij nesten van vier $(4,8 \%)$ of vijf kittens $(3,5 \%)(P=0,016)$.

\section{ABSTRACT}

Although breeding pedigree cats is increasingly popular, there is still a lack of scientific data about parturition and the problems that might occur. The incidence of kitten mortality varies between 15 and $40 \%$. In this study, information was collected by means of a questionnaire on six popular breeds in Flanders. Information from 151 litters was obtained. An average gestation length of $65.1 \pm 2.64$ days and an average litter size of $4.5 \pm 1.73$ kittens were extracted from the questionnaire. The litter size in cats older than four years old was found to be significantly smaller (3.6 \pm 1.48 kittens) than in younger cats $(4.8 \pm 1.71$ kittens $)(\mathrm{P}=0.001)$. A caesarean section was performed in $8.5 \%$ of the litters. On average, in $6.8 \%$ of the litters, a congenital defect in one or more kittens was reported. A mortality rate of $21.4 \%$ was observed from birth until weaning. A significant higher rate of stillbirths was observed in small (1-3 kittens: $12.2 \%)$ and in large litter sizes (6-9 kittens: $7.3 \%)$ than in litters of four $(4.8 \%)$ or five $(3.5 \%)$ kittens $(\mathrm{P}=0.016)$.

\section{INLEIDING}

Kittensterfte vóór de speenleeftijd komt zeer vaak voor bij raskatten en kan variëren tussen 15 en $40 \%$ gedurende de eerste twaalf levensweken. Het hoogste sterftepercentage wordt gezien bij de geboorte en tijdens de eerste levensweek (Hoskins, 2001; Lawler en Monti, 1984; Davidson, 2014). In een studie van Roth (1987) werd 10,2\% doodgeboren, $15,2 \%$ stierf binnen de week en $27,1 \%$ van de kittens bereikte de leeftijd van één jaar niet. In een andere grote studie bij raskatten was het gemiddelde sterftecijfer $34,5 \%$ gerekend vanaf de geboorte tot de leeftijd van één jaar. Vanaf de geboorte tot vóór de speenleeftijd varieerde het sterftecijfer van 15 tot $27 \%$ (Bücheler, 1999). Vaak is de oorzaak moeilijk te achterhalen en wordt geen diagnose gesteld omdat er slechts vage symptomen optreden. Er kan echter een onderscheid gemaakt worden 
tussen niet-infectieuze en infectieuze oorzaken van kittensterfte. Niet-infectieuze oorzaken worden vaak beschreven bij sterfte die optreedt tijdens de eerste levensweek (Bücheler, 1999; Meade, 2014). Naast dystokie behoren neonatale iso-erytrolyse en congenitale of genetische afwijkingen tot de niet-infectieuze oorzaken van kittensterfte. Een laag geboortegewicht of immature kittens, problemen bij het moederdier, zoals nutritionele factoren en omgevingsfactoren, zijn eveneens voorbeelden van niet-infectieuze oorzaken van kittensterfte (Bücheler, 1999; Francois et al., 2006). Infectieuze oorzaken treden voornamelijk op bij kittens rond de periode van drie tot vier weken ouderdom (Bücheler, 1999). Hierbij kan een onderscheid gemaakt worden tussen virale, bacteriële en parasitaire oorzaken, waarbij virale infecties het vaakst beschreven worden als oorzaak van infectieuze problemen en sterfte bij kittens. Bacteriële en parasitaire infecties zijn zeker niet onbelangrijk en kunnen in extreme gevallen eveneens sterfte tot gevolg hebben (Bücheler, 1999; Hoskins, 2001; Meade, 2014).

Ondanks deze hoge sterftecijfers is er weinig wetenschappelijke informatie beschikbaar omtrent de oorzaken van deze sterfte en de eventuele problemen die kunnen optreden tijdens de partus en neonatale ontwikkeling (Musters et al., 2011). Bovendien zijn er weinig studies uitgevoerd omtrent de normale partus. Nochtans wordt het fokken van raskatten steeds populairder en is het zowel voor dierenartsen als voor eigenaars van cattery's belangrijk om referentiewaarden te hebben betreffende de normale reproductieve parameters.

Het doel van deze studie was om via een vragenlijst, gestuurd naar fokkers in Vlaanderen, gegevens te verzamelen omtrent de partus bij raskatten en sterfte vanaf de geboorte tot de speenleeftijd en deze te vergelijken met gegevens uit andere landen. Er werd ook getracht om significante ras- of leeftijdsverschillen op te sporen.

\section{MATERIAAL EN METHODEN}

\section{Selectie van de fokkers}

Via een begeleidende e-mail werden fokkers van zes populaire rassen in Vlaanderen bereikt. In totaal werden 359 fokkers gecontacteerd waarvan 171 Britse korthaar-fokkers, 46 ragdoll-fokkers, 59 maine coon-fokkers, 42 pers-fokkers, 22 siamees-fokkers en 19 Scottish-fold-fokkers over heel Vlaanderen. Er werd gevraagd om via een vragenlijst informatie door te geven over nesten geboren in 2017. Zowel nesten zonder problemen als nesten met kittensterfte werden opgenomen in de studie. Per geboren nest werd gevraagd om een aparte vragenlijst in te vullen.

\section{De vragenlijst}

De vragenlijst werd opgemaakt via Google For- mulieren en bestond uit twintig gesloten vragen met telkens verschillende antwoordmogelijkheden. De eigenaars konden slechts één antwoord per vraag doorgeven of hadden de mogelijkheid om 'ander antwoord' te kiezen en zelf een antwoord te formuleren. In de eerste reeks vragen werd naar algemene informatie over de kattin en de kater gevraagd, zoals het ras, de leeftijd, de bloedgroep van zowel kater als kattin en de pariteit van de kattin. Ook werd nagegaan of de kattin bij vorige nesten reeds een keizersnede had ondergaan. In het tweede deel van de vragenlijst werd meer informatie over het desbetreffende nest verzameld. Hierbij werd gevraagd naar drachtduur, nestgrootte en kittensterfte in het aangegeven nest. De kittensterfte werd opgedeeld in verschillende perioden, namelijk doodgeboorte, sterfte binnen de 48 uur, sterfte tijdens de eerste levensweek en/of sterfte tot aan de speenleeftijd, waarbij telkens het aantal gestorven kittens kon aangegeven worden in de betreffende periode. Als laatste werd gevraagd naar de speenleeftijd en welke melk de kittens hadden gekregen.

\section{Analyse van de data}

De statistische verwerking gebeurde via het programma SPSS. Continu-variabelen werden geanalyseerd met behulp van een ANOVA-test, terwijl voor de categorisch-variabelen de chi-square-test werd toegepast.

De data worden weergegeven als het gemiddelde \pm standaarddeviatie of als percentage. Verschillen waarbij de $\mathrm{P}$-waarde kleiner is dan 0,05 worden als significant beschouwd.

\section{RESULTATEN}

\section{Algemene informatie}

De enquête werd 151 keer ingevuld: 64 enquêtes werden voor Britse korthaar ingevuld, 33 voor maine coon, 33 voor ragdoll, 10 voor pers, 6 voor siamees en 5 voor Scottish fold. In totaal werd over 679 kittens informatie verzameld: 280 Britse korthaar-kittens, 160 maine coon-kittens, 157 ragdoll-kittens, 36 kittens bij de pers, 28 kittens bij de siamees en 18 bij de Scottish fold. In Tabel 1 wordt een samenvatting weergegeven van de rasspecifieke data die verzameld werden gedurende deze studie.

De gemiddelde leeftijd van alle kattinnen die deelnamen aan de studie was $2,8 \pm 1,83$ jaar. De jongste kattin in de studie was jonger dan één jaar en de oudste kattin acht jaar. Er werd geen significant verschil tussen de verschillende rassen opgemerkt. Van de deelnemende kattinnen in deze studie had 65,6\% reeds eerder een nest gehad met een gemiddelde van $1,4 \pm 1,54$ nesten. Ook hier werd geen significant verschil tussen de verschillende rassen opgemerkt. Bij pluripare katten bleek $9,1 \%$ in het verleden een keizersnede te hebben ondergaan. 
Tabel 1. Samenvatting van de data weergegeven per ras.

\begin{tabular}{|c|c|c|c|c|c|c|c|c|c|c|c|}
\hline Ras & $\begin{array}{c}\text { Totaal } \\
\text { aantal } \\
\text { enquêtes/ } \\
\text { kattinnen }\end{array}$ & $\begin{array}{l}\text { Totaal } \\
\text { aantal } \\
\text { kittens }\end{array}$ & $\begin{array}{l}\text { Gemid- } \\
\text { delde } \\
\text { leeftijd } \\
\text { van de } \\
\text { kattin }\end{array}$ & $\begin{array}{c}\text { Gemid- } \\
\text { deld \% } \\
\text { primipare } \\
\text { kattinnen }\end{array}$ & $\begin{array}{l}\text { Gemid- } \\
\text { delde } \\
\text { dracht- } \\
\text { duur } \\
\text { (\# kittens) }\end{array}$ & $\begin{array}{l}\text { Gemid- } \\
\text { delde } \\
\text { nest- } \\
\text { grootte }\end{array}$ & $\begin{array}{l}\text { Gemid- } \\
\text { deld \% } \\
\text { keizer- } \\
\text { sneden } \\
\text { kittens }\end{array}$ & $\begin{array}{l}\text { Gemid- } \\
\text { deld \% } \\
\text { dood- } \\
\text { geboren } \\
48 \text { uur }\end{array}$ & $\begin{array}{l}\text { Gemid- } \\
\text { deld \% } \\
\text { kitten- } \\
\text { sterfte } \\
48 \text { uur }\end{array}$ & $\begin{array}{l}\text { Gemid- } \\
\text { deld \% } \\
\text { kitten- } \\
\text { sterfte } \\
\text { speen- } \\
\text { - week } 1\end{array}$ & $\begin{array}{l}\text { Gemid- } \\
\text { deld \% } \\
\text { kitten- } \\
\text { sterfte } \\
\\
\text { leeftijd }\end{array}$ \\
\hline Britse korthaar & 64 & 280 & 2,9 & 35,9 & 65,7 & 4,4 & 9,4 & 6,8 & 4,3 & 2,9 & 0,7 \\
\hline Maine coon & 33 & 160 & 2,8 & 33,3 & 65,1 & 4,8 & 6,1 & 6,9 & 6,9 & 3,8 & 2,5 \\
\hline Ragdoll & 33 & 157 & 2,3 & 36,4 & 64,3 & 4,8 & 3 & 7 & 7,6 & 12,1 & 5,1 \\
\hline Pers & 10 & 36 & 3,2 & 39 & 64,8 & 3,6 & 3 & 5,6 & 11,1 & 16,7 & 2,8 \\
\hline Siamees & 6 & 28 & 3 & 16,7 & 65,3 & 4,7 & 16,7 & 3,6 & 10,7 & 10,7 & 3,6 \\
\hline Scottish fold & 5 & 18 & 2,6 & 40 & 63,3 & 3,6 & 0 & 0 & 0 & 0 & 0 \\
\hline Totaal & 151 & 679 & & & & & & & & & \\
\hline Gemiddelde \pm SD & & & $2,8 \pm 1,83$ & 34,4 & $65,1 \pm 2,64$ & $4,5 \pm 1,73$ & 8,6 & 6,5 & 6,2 & 6,2 & 2,4 \\
\hline Range & & & $<1-8$ & $0-100$ & $52-70$ & $0-100$ & $0-100$ & $0-100$ & $0-100$ & $0-100$ & $0-100$ \\
\hline
\end{tabular}

$\mathrm{SD}=$ standaard deviatie

\section{Drachtduur}

Het overgrote deel van de fokkers (83\%) telt de lengte van de dracht vanaf de eerste dag dat de kattin bij de kater gezet wordt; in de overige gevallen wordt geteld vanaf de tweede of derde dag. Voor deze laatste werd de doorgegeven drachtduur gecorrigeerd, zodat de gemiddelde drachtduur geteld vanaf de eerste dag bij de kater 65,1 $\pm 2,64$ dagen bedroeg (Figuur 1). De gemiddelde drachtduur tussen de rassen onderling varieerde van 63,3 dagen tot 65,8 dagen, maar een significant rasverschil werd niet opgemerkt. De kortste drachtduur in deze studie bedroeg 52 dagen bij één nest van een maine coon-kat en de langste drachtduur bedroeg 70 dagen bij drie nesten, namelijk bij een ragdoll, pers en een Britse korthaar. Er was geen effect van leeftijd, noch van nestgrootte op de drachtduur in deze studie.

\section{Nestgrootte}

De gemiddelde nestgrootte bij de 151 nesten in deze studie bedroeg 4,5 $\pm 1,73$ kittens met een variatie van 1 tot 9 kittens en was gelijkaardig voor alle rassen (Figuur 2). Wanneer de leeftijd van de kattin in beschouwing wordt genomen, werd een significant verschil tussen de nestgrootte vastgesteld bij katten ouder dan vier jaar, die een kleinere nestgrootte hadden $(3,6 \pm 1,48$ kittens $)$ dan bij jongere katten $(4,8 \pm$ $1,71$ kittens) $(\mathrm{P}=0,001)$ (Figuur 3$)$. De primipare kattinnen hadden een gemiddelde nestgrootte van 4,6 \pm 1,94 kittens en bij de niet-primipare kattinnen was de gemiddelde nestgrootte $4,4 \pm 1,61$ kittens.

\section{Geslachtsratio}

Het aandeel mannelijke kittens $(\mathrm{n}=372,56 \%)$ was hoger dan het aandeel vrouwelijke kittens $(\mathrm{n}=291$, 44\%). Bij drie van de 151 nesten werd het geslacht van de kittens niet doorgegeven.
Spenen

De overgrote meerderheid van de kittens $(51,7 \%)$ werd vóór de leeftijd van acht weken gespeend (75/145). Bij 76\% (114/150) van de nesten werden de kittens grootgebracht met moedermelk. Opvallend is dat $23,3 \%(35 / 150)$ van de nesten werd bijgevoederd met commerciële melk. In twee gevallen werd poedermelk bijgegeven tijdens een hittegolf om zo de moeder te ontlasten; in twee andere nesten werd extra poedermelk bijgegeven aan bepaalde kittens wegens een lager geboortegewicht dan de nestgenoten. Geitenmelk werd in één nest gebruikt om de kittens bij te voederen naast de moedermelk. Slechts in één nest $(0,7 \%)$ werden de kittens volledig met de hand grootgebracht met commerciële melk aangezien de melkproductie bij de kattin niet op gang kwam.

\section{Keizersnede}

Voor het nest geboren in 2017 werd gevraagd of er een keizersnede werd uitgevoerd. Bij 8,6\% (13/151) van de kattinnen werden één of meer kittens via een keizersnede geboren. Er werd geen significant verschil tussen de rassen onderling gevonden en de nestgrootte had evenmin een invloed. Daarentegen kon een trend van meer keizersneden opgemerkt worden bij een stijgende leeftijd van de katten: bij kattinnen ouder dan vier jaar onderging $17,5 \%$ een keizersnede, terwijl slechts $5,4 \%$ van de kattinnen jonger dan vier jaar een keizersnede had ondergaan $(\mathrm{P}=0,058)(\mathrm{Fi}-$ guur 4).

Van de dertien nesten die via een keizersnede geboren werden, werden vier keizersneden vooraf gepland (30,8\% electieve keizersneden), terwijl de andere negen keizersneden uitgevoerd werden door problemen tijdens de partus (69,2\% spoedkeizersneden). Meer electieve keizersneden werden uitgevoerd bij katten ouder dan vier jaar, namelijk $85,7 \%$ in vergelijking met $0 \%$ bij katten jonger dan vier jaar $(\mathrm{P}=0,008)$. 


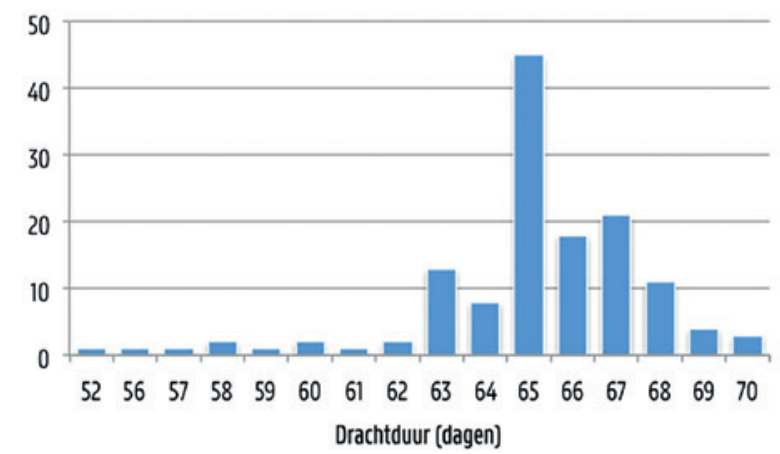

Figuur 1. De gemiddelde drachtduur in dagen (x-as) uitgedrukt ten opzichte van het aantal katten (y-as).

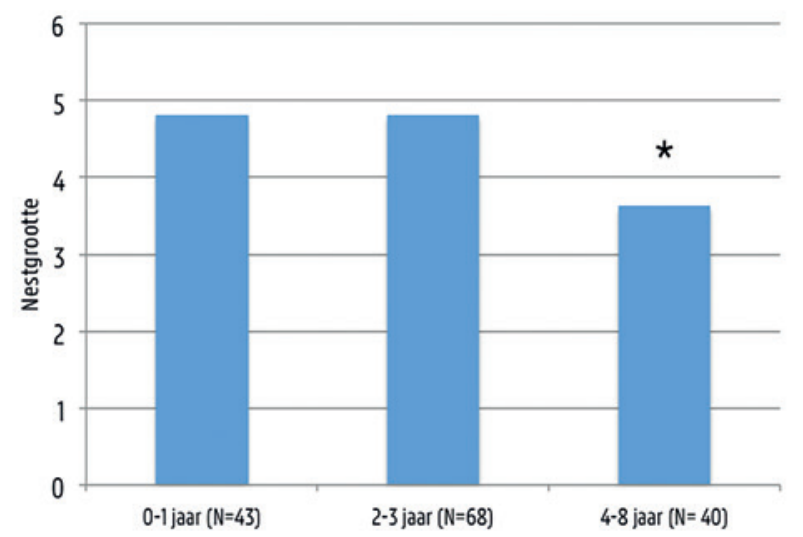

Figuur 3. Nestgrootte weergegeven in functie van de leeftijd van de kattin met $\mathbf{N}=$ aantal kattinnen. Significante verschillen $(P<0,05)$ worden aangegeven met een asterisk.

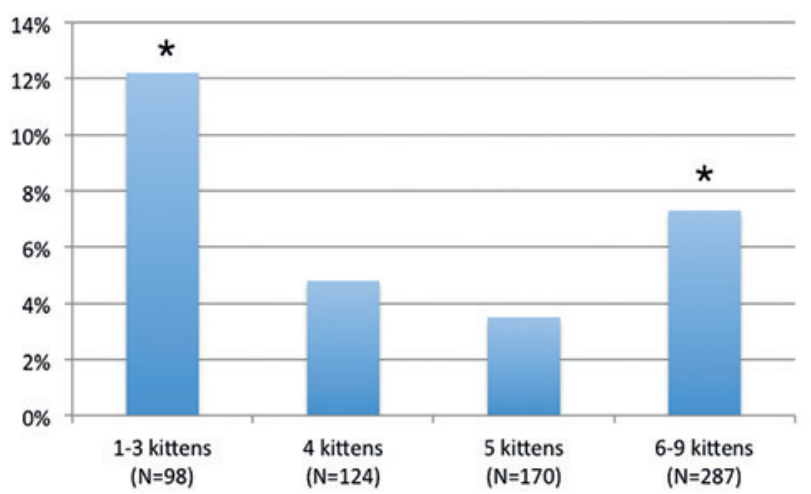

Figuur 5. Percentage doodgeboren kittens in functie van de nestgrootte. Significante verschillen $(P<0,05)$ worden aangegeven met een asterisk.

Het totale sterftepercentage van kittens afkomstig van kattinnen, waarbij een keizersnede werd uitgevoerd, bedroeg $39,1 \%$.

\section{Congenitale afwijkingen}

Macroscopische anatomische afwijkingen bij één of meer kittens werden bij 6,8\% van de 146 nesten gerapporteerd. Bij vijf nesten werd deze vraag niet

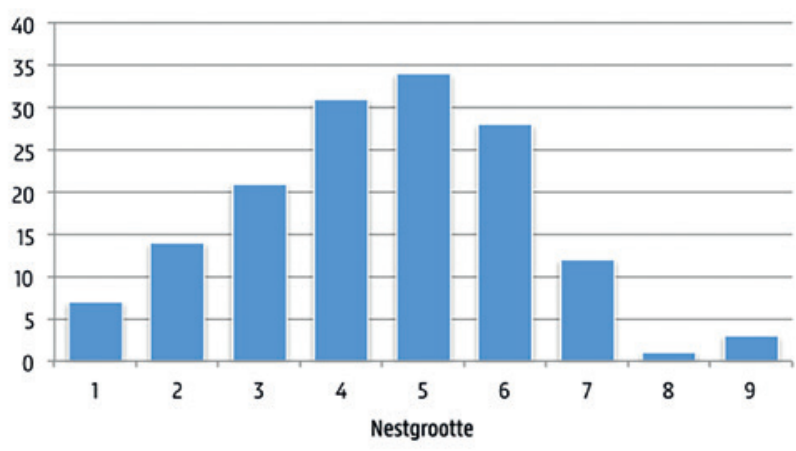

Figuur 2. Verdeling van de nestgrootte weergegeven in aantal kittens ( $x$-as) ten opzichte van het aantal katten (y-as).

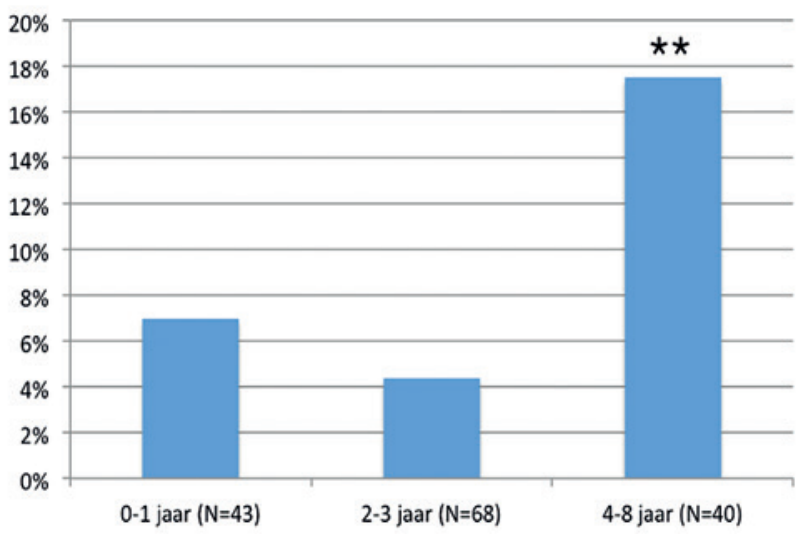

Figuur 4. Percentage keizersneden weergegeven in functie van de leeftijd van de kattin. De geobserveerde trend $(P=0,058)$ wordt aangegeven met een dubbele asterisk.

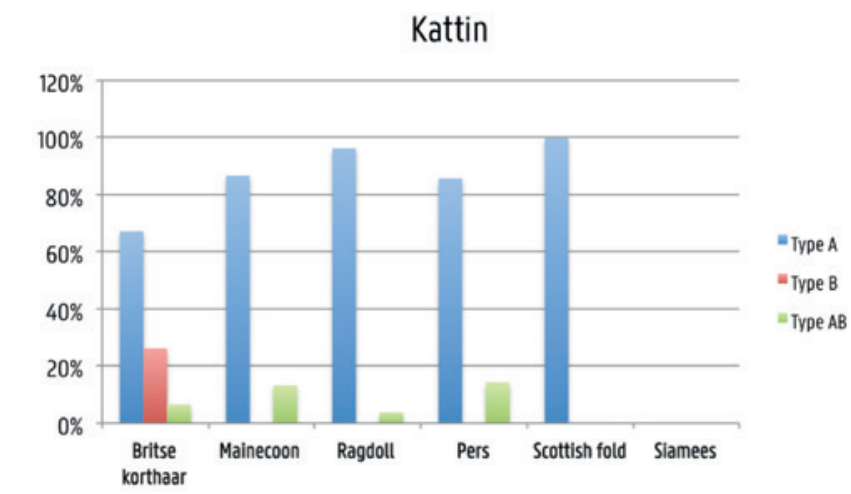

Figuur 6. Verdeling van de verschillende bloedgroepen bij de kattin ( $x$-as) procentueel voorgesteld (y-as).

ingevuld. De anatomische afwijkingen die gespecificeerd werden, waren hernia umbilicalis, atresia ani, gespleten gehemelte en cryptorchidie. Er werden geen significante verschillen tussen rassen of leeftijden van de kattinnen waargenomen. Ook had de nestgrootte geen invloed op het voorkomen van congenitale afwijkingen. Er werd in deze studie niet gevraagd naar het aantal kittens per nest met een anatomische afwijking . 


\section{Kittensterfte}

Het totale sterftepercentage bij kittens bedroeg in deze studie 21,4\% (145/679) gerekend vanaf de geboorte tot aan de speenleeftijd. Dit sterftepercentage werd onderverdeeld in vier perioden: 1) doodgeboorte, 2) kittensterfte binnen 48 uur, 3) kittensterfte binnen de eerste levensweek en 4) kittensterfte tot aan de speenleeftijd ( \pm 8 weken).

In deze studie werd 6,6\% (45/679) van de kittens doodgeboren. Als het aantal doodgeboorten per nestgrootte bekeken wordt, is er een significant verschil: er werd een hoger aantal doodgeboorten geconstateerd bij kleinere nestgroottes (1-3 kittens: 12,2\%) en grote nesten (6-9 kittens: 7,3\%) dan bij nesten met vier $(4,8 \%)$ of vijf kittens $(3,5 \%)(\mathrm{P}=0,016)$ (Figuur 5). Daarnaast stierf $6,2 \%(42 / 679)$ van de kittens binnen de eerste 48 uur, $6,2 \%(42 / 679)$ vanaf 48 uur tot de eerste levensweek en vanaf de eerste levensweek tot aan de speenleeftijd bedroeg het sterftepercentage $2,4 \%(16 / 679)$. Er werden geen significante verschillen opgemerkt wanneer de kittensterfte tussen rassen of tussen verschillende leeftijd van de kattinnen vergeleken werd.

\section{Bloedgroepen}

In deze studie werd ook naar de bloedgroep gevraagd van zowel kater als kattin. Deze kan fenotypisch bestaan uit bloedgroep $\mathrm{A}$, die het meest voorkomt, en bloedgroep B. Daarnaast bestaat er ook een derde, zeldzame bloedgroep AB. Genetisch worden de bloedgroepen A en B bepaald door allel A en b, waarbij allel A dominant is over b. Genotypisch kan een kat met bloedgroep $\mathrm{A}$ of $\mathrm{AB}$ ook drager zijn van het b-allel. Bij de 233 katten (zowel katers als kattinnen), waarbij de bloedgroep bekend was, had 74,2\% bloedgroep A, 17,6\% bloedgroep B en slechts 8,2\% bloedgroep AB. AB-kattinnen kwamen voor bij de Britse korthaar $(6,6 \%: 4 / 61)$, ragdoll $(3,8 \%: 1 / 26)$, maine coon $(13,3 \%: 2 / 15)$ en pers $(14,3 \%: 1 / 7)$. In dit onderzoek waren de katten met bloedgroep type A bij alle rassen het meest vertegenwoordigd. Bij de populatie siamezen in deze studie was voor geen enkel nest de bloedgroep van de ouderdieren bekend.

Bij de Britse korthaar-kattinnen werd het grootste aantal type B-katten gevonden (26,2\%: 16/61), terwijl bij de andere rassen geen type B-kattinnen werden opgegeven (Figuur 6). Bij vijf nesten van Britse korthaar-kattinnen werd de combinatie van een B-kattin $\mathrm{x}$ A-kater of AB-kater gemaakt. De kittens met bloedgroep A, die geboren worden uit deze combinatie, lopen een risico op neonatale iso-erytrolyse door de opname van colostrum met anti-A antistoffen, die in hoge concentraties aanwezig zijn bij B-katten en een sterke hemolyserende werking hebben. Bij deze combinatie is het noodzakelijk om de kittens gedurende de eerste 24 uur weg te houden van de moederpoes om de opname van colostrum te verhinderen (Snoeck et al., 2013). In 24,5\% (37/151) van de gevallen werd de bloedgroep niet ingevuld of was ze onbekend, waardoor ook deze kittens een groter risico liepen op neonatale iso-erytrolyse.

\section{DISCUSSIE}

Het doel van deze studie was om referentiewaarden te verzamelen omtrent de dracht en partus bij raskatten alsook omtrent kittensterfte zodat deze parameters kunnen vergeleken worden met resultaten van eerdere, Europese studies. In de voorliggende studie kon het responspercentage niet bepaald worden aangezien de enquête volledig anoniem is verlopen en eigenaars meerdere formulieren konden invullen indien er in 2017 meerdere nesten bij hen werden geboren. Het nadeel van een enquête is dat enkel gemotiveerde fokkers deelnemen, waardoor dit de resultaten kan beinvloeden. Daarnaast willen niet alle fokkers deze informatie delen en dit kan ook een reden zijn waarom sommige vragen niet werden ingevuld.

De gemiddelde drachtduur in deze studie is vergelijkbaar met de drachtduur in een studie van Jemmett en Evans (1977), Sparkes et al. (2006) en van Musters et al. (2011). Net zoals in de studie van Musters et al. (2011) werden in deze studie geen rasverschillen gevonden betreffende de drachtduur; dit in tegenstelling tot Sparkes et al. (2006). In tegenstelling tot deze studie werd in eerdere studies wel een significant langere drachtduur gevonden bij kattinnen met een kleinere nestgrootte (Sparkes et al., 2006, Musters et al., 2011). De gemiddelde nestgrootte in deze studie is vergelijkbaar met de nestgrootte in de studie van Sparkes et al. (2006), Musters et al. (2011) en Fournier et al. (2017), maar in de studie van Ström Holst en Frössling (2009) ligt de gemiddelde nestgrootte iets lager, namelijk 3,7 $\pm 1,5$ kittens. De invloed van de pariteit op de nestgrootte werd in de voorliggende studie niet bestudeerd. Een significante invloed van de leeftijd van de kattin op de nestgrootte werd gevonden in deze studie; de leeftijdsinvloed werd ook bevestigd in een studie van Johnstone (1987) en Ström Holst en Frössling (2009). Rasverschillen voor wat betreft nestgrootte werden niet waargenomen in tegenstelling tot in de studie van Sparkes et al. (2006) en Ström Holst en Frossling (2009). Net zoals in de studie van Musters et al. (2011) waren in deze studie meer mannelijke kittens aanwezig dan vrouwelijke kittens, en het aantal nesten waarbij de kattin een keizersnede onderging, was gelijkaardig in de studie van Sparkes et al. (2006) $(8,0 \%)$ en Ström Holst en Frössling (2009) $(7,0 \%)$. Rasinvloeden werden hier, net zoals in de studie van Sparkes et al. (2006) en Ström Holst en Frössling (2009), niet gevonden.

Het percentage congenitale afwijkingen lag lager dan de $14,3 \%$ congenitale afwijkingen gevonden in de studie van Sparkes et al. (2006); daarbij werd echter niet gevraagd naar het type afwijking. Het sterftepercentage bij kittens in deze studie was beduidend hoger 
dan de $15,7 \%$ sterfte in de studie van Fournier et al. (2017). Bij 6,6\% van de kittens werd doodgeboorte vastgesteld, wat iets lager is dan $8,5 \%$ doodgeboorten in de studie van Fournier et al. (2017). Sparkes et al. (2006) vonden net zoals in deze studie dat het grootste aandeel sterften vóór de leeftijd van één week voorkomen. Er werd een hoger aantal doodgeboorten geconstateerd bij kleinere nestgroottes (1-3 kittens: 12,2\%) en grote nesten (6-9 kittens: 7,3\%) dan bij nesten met vier $(4,8 \%)$ of vijf kittens $(3,5 \%)$. De verdeling van de bloedgroepen was gelijkaardig in andere studies met voornamelijk een hoger percentage type B-kattinnen bij de Britse korthaar dan bij andere rassen (Meade, 2014). Echter, in deze studie werd niet nader gevraagd of de gerapporteerde bloedgroep bepaald werd via serologie of via een DNA-test. Via serologie kan een onderscheid gemaakt worden tussen de drie bloedgroepen $\mathrm{A}, \mathrm{B}$ en $\mathrm{AB}$, maar het is niet bekend of de katten met bloedgroep $\mathrm{A}$ of $\mathrm{AB}$ drager zijn van het allel b. Via genetische testen wordt in de meeste gevallen enkel een onderscheid gemaakt tussen bloedgroep $A$ of $A B$ enerzijds en bloedgroep $B$ anderzijds. Bij de katten met bloedgroep $A$ of $A B$ wordt ook onderzocht of zij al dan niet drager zijn van het allel b. Recent werd echter een genetische test ontwikkeld die ook verder een onderscheid kan maken tussen bloedgroep A en AB (Kehl et al., 2018).

\section{CONCLUSIE}

Als conclusie kan gesteld worden dat de resultaten van deze studie meer inzicht verschaffen in de parameters omtrent het fokken van raskatten in Vlaanderen en kunnen helpen om meer referentiewaarden te genereren van de dracht en partus evenals neonatale sterfte bij kittens. Het hoge sterftecijfer van $21,4 \%$ in deze studie mag zeker niet onderschat worden en in de toekomst zou meer diagnostisch onderzoek moeten gebeuren om een betere kennis te verwerven van de mogelijke oorzaken van deze sterfte. De resultaten uit deze studie kunnen tevens gebruikt worden om een grotere bewustwording bij fokkers te bekomen omtrent bloedgroepbepaling, opvolging van de dracht en postnatale opvolging van de kittens. Problemen bij kittens zouden hierdoor sneller opgemerkt kunnen worden, waardoor tijdig een diagnose en behandeling kunnen ingesteld worden.

\section{REFERENTIES}

Bücheler J. (1999). Fading kitten syndrome and neonatal isoerythrolysis. Veterinary Clinics of North America: Small Animal Practice 29, 853-870.

Davidson A.P. (2014). Neonatal resuscitation: Improving the outcome. Veterinary Clinic Small Animal 44, 191204.
Fournier A., Masson M., Corbière F., Mila H., Mariani C., Grellet A., Chastant-Maillard S. (2017). Epidemiological analysis of reproductive performances and kitten mortality rates in 5,303 purebred queens of 45 different breeds and 28,065 kittens in France. Reproduction in Domestic Animals 52, 153-157.

Francois B., Rijsselaere T., Van Soom A. (2006). Niet-infectieuze oorzaken van neonatale problemen en sterfte bij kittens. Vlaams Diergeneeskundig Tijdschrift 75, 439449.

Hoskins J.D. (2001). Puppy and kitten losses. In: Hoskins J.D. (editor). Veterinary Pediatrics: Dogs and Cats from Birth to Six Months. Third edition, Saunders Elsevier, Philadelphia, USA, p. 57-61.

Jemmett J.E., Evans J.M. (1977). A survey of sexual behaviour and reproduction of female cats. Journal of Small Animal Practice 18, 31-37.

Johnstone I. (1987). Reproductive patterns of pedigree cats. Australian Veterinary Journal 64, 197-200.

Kehl A., Heimberger K., Langbein-Detsch I., Boehmer S., Raj K., Mueller E., Giger U. (2018). Molecular characterization of blood type $\mathrm{A}, \mathrm{B}$, and $\mathrm{C}(\mathrm{AB})$ in domestic cats and a CMAH genotyping scheme. PloS one, 13, $\mathrm{e} 0204287$.

Lawler D.F., Monti K.L. (1984). Morbidity and mortality in neonatal kittens. American Journal of Veterinary Research 45, 1455-1459.

Meade C. (2014). Fading syndrome in kittens. In Practice 36, 266-276.

Musters J., de Gier J., Kooistra H.S., Okkens A.C. (2011). Questionnaire-based survey of parturition in the queen. Theriogenology 75, 1596-1601.

Roth J.A. (1987). Possible association of thymus dysfunction with fading syndromes in puppies and kittens. Veterinary Clinics of North America: Small Animal Practice 17, 603-616.

Silvestre-Ferreira A.C., Pastor J. (2010). Feline neonatal isoerythrolysis and the importance of feline blood types. Veterinary Medicine International, Article ID 753726.

Snoeck F., Rijsselaere T., Van Soom A. (2013). Neonatale iso-erytrolyse bij de kat. Vlaams Diergeneeskundig Tijdschrift 82, 337-344.

Sparkes A.H., Rogers K., Henley W.E., Gunn-Moore D.A., May J.M., Gruffydd-Jones T.J., Bessant C. (2006). A questionnaire-based study of gestation, parturition and neonatal mortality in pedigree breeding cats in the UK. Journal of Feline Medicine and Surgery 8, 145-157.

Ström Holst B., Frössling J. (2009). The Swedish breeding cat: population description, infectious diseases and reproductive performance evaluated by a questionnaire. Journal of Feline Medicine and Surgery 11, 793-802. 